A small number of children attend school inadequately clad. There is, however, widespread com. ment about the unsuitable types of shoes worn by many children, especially older girls. A school doctor in Hertfordshire reported that younger children were well shod, but that "many girls of secondary school age would not be guided otherwise than by the dictates of fashion".

The report says that it is doubtful whether children will refrain from smoking so long as they see their parents and teachers enjoying the habit. A survey of about 3,500 boys and girls in two grammar schools and four modern secondary schools in a county borough near London shows that eight per cent of the children are 'regular' smokers-the smoking of five cigarettes a week being defined as regular for the purposes of the survey. One third of the children aged 14-16 who are 'regular' smokers smoke more than twenty cigarettes a week. Another survey carried out in Oxfordshire of about 8,300 children shows that nearly 1,600 are smokers and spend $£ 4,350$ a year on cigarettes. Nearly half these children say that they have heard that there is some connexion between cigarette smoking and lung cancer.

The report emphasizes that, generally, facilities are adequate for medical treatment, but are seriously inadequate for dental treatment; the national shortage of dentists is the main deficiency. The school dental service is able to treat only a little more than half the number of children who require treatment. A large number, many of whom attend non-maintained schools, are treated by the general dental service, but hundreds of thousands are neglected.

In 1959 , for the first time, the number of part. time dentists did not balance the number of wholetime dentists who retired or who left the service.

Special surveys of the teeth of the 5-12 year old children in eight representative areas show that deterioration of the teeth was less in five-year olds, but greater in twelve-year old children between 1953 and 1958 than between 1948 and 1953. "It is significant that during the period 1948-1958 sugar consumption per head in the United Kingdom rose from $88.3 \mathrm{lbs}$. in 1948 to $103 \cdot 1 \mathrm{lbs}$. in 1953 and $120.7 \mathrm{lbs}$. in $1958^{\prime \prime}$, states the report.
The report of the working party set up in 1949 "to direct and organize an investigation on the prophylactic effects of the local application of a solution of fluoride to school children's teeth", is published as an appendix to the report. The working party considers that the application of a fluoride solution to the teeth is not a worthwhile preventive measure in the conditions of the investigation, that is, when the treatment is given on a wide scale in the public dental service. This may well enhance the interest already being taken in alternative methods of caries prevention, such as tluoridation of drinking water and the dental health education of the public, and especially children, in such matters as proper diet and the cleansing of teeth.

A notable feature of the work of the School Health Service in the years under review is the increased attention given to children with emotional or be. haviour problems, and also of those with speech defects, but there was a serious shortage of child guidance clinic staff and of speech therapists. Much attention was paid to handicapped children; 54 new special schools, with accommodation for 5,732 children, were opened in 1958 and 1959, bringing the total number of handicapped children in special schools to more than 60,000 . Much interest, too, was taken in children with defective hearing, and an increasing number of local education authorities employed peripatetic teachers of the deaf to visit children in ordinary schools, or opened special classes in ordinary schools for partially hearing children. During this period a large number of the new Medresco transistor hearing aids were supplied to school children.

Sir John insists that a school health service cannot ignore the challenge of children from problem families, of those who have been before the courts, or of promiscuity among some older adolescents. These boys and girls formed a small minority of the school population, but they presented "a tough problem to the medical, education and social services-three services that must work together".

Appendixes to the report include, in addition to the usual statistical tables, a list of the research projects being undertaken in the school health service and an index to The Health of the School Child for the period 1935-57.

\title{
STRENGTH AND PROPERTIES OF TIMBER
}

$\mathrm{R}^{\mathrm{r}}$ ESEARCH into timbers is undertaken in England at the Forest Products Research Laboratory, Princes Risborough, and is under the auspices of the Department of Scientific and Industrial Research. F'orest Products Research Bulletin No. 45, entitled "The Strength and Properties of Timber", by F. H. Armstrong *, supersedes two earlier ones on the same subject and contains fresh material. Information on the properties of no fewer than 172 kinds of timber is presented in the proportion of some 37 home-grown timbers to 136 imported timbers, figures which may appear to some to be rather disproportionate, but the Laboratory has

* Pp. vi $+34+8$ plates. (London : H.M. Stationery Office, 1960.) 3s. $6 d$. net. done a useful service to Commonwealth countries while not actually ignoring home-grown material, which has been handled more intensively. The technique of timber-testing has made considerable advances in recent years, and one new development in England has been the adoption of the 'Monnin' system, which makes use of 2-cm. square instead of 2 -in. square test-pieces, and is thus more suitable for small-diamster trees.

The gist of this Bulletin consists of three tabular statements occupying about 16 pages. The physical and mechanical properties of home-grown timbers are given in Table 1 , those of imported timbers, based on 2-in. test-pieces, in Table 2, and those of imported timbers, based on 2.cm. test-pieces, in 
Table 3. The contents of species in une last two tables do not conform. The data refer to the eight tests made, namely, six tests of physical properties, of (a) static bending, (b) impact bending, (c) compression parallel to grain, (d) hardness, $(e)$ shear parallel to grain, and $(f)$ cleaveg;, supplemented by physical tests of moisture content and specific gravity. These tests and the apparatus used are described in some detail with the help of photographs. Since the most important factors which influence the strength of a timber are its moisture content and specific gravity, these are dealt with in some detail. Regarding the latter, it appears that, in respect of the actual wood substance, it is for all practical purposes the same for all species, but that the amount of that substance varies with the species, so that there is, in fact, a wide variation of specific gravity, and strength, not only between different species but also within each species. The strength values given in the tables are primarily intended for a comparison of species. Here it must be pointed out that while the pieces tested may be representative of variation of the properties within individual trees or small groups of trees, they can scarcely be said to be fully, or even fairly, representative of any species for the whole range of conditions under which it is grown. The largest number of trees or planks tested refer to Weymouth pine (56), Corsican pine (38), beech (36) and Scots pine (35), whereas for some tropical species a single tree has provided all the test-pieces.

In this connexion the presentation of the data can be criticized on the grounds that the first letter of a name is not a good scientific basis for grouping, although it is admittedly useful in locating a species within a group. It does seem incongruous, for example, to find horse chestnut sandwiched in Table 3 between dahoma and North Bornean kapur. The grouping adopted here might have been taken a little farther ; there would have been no disadvantage if the timbers of each country had been grouped together-in alphabetical order.

An interesting and unexpected feature of the Bulletin is an introduction to simple statistical methods useful in comparing results or testing relationships between variables, and justifiably applied here in handling the data from many samples from one tree or group of trees from one source. The recognition of the possible importance of such factors as capacity to resist fungous attack or the effects of atmospheric fluctuations seems to indicate a new outlook. The value of the graphs presented in Fig. 5, showing the relationship between specific gravity and maximum compressive strength, is much impaired by the absence of a key to link up the plotted numbers with the corresponding species.

This publication is a useful contribution to our knowledge of the properties of a wide range of timbers, many with very odd names, and it should be of value to importers and to timber-growers in Commonwealth countries who are endeavouring to find markets for so-called 'secondary' timber trees. To the layman it should convey some idea of the widely varying character of timber as a raw material.

\section{DUCTILE BERYLLIUM}

COME fifty years of work on the production of $S$ ductile beryllium would appear to have come to full fruition by the announcement by the Chesterfield Tube Co., Ltd., a subsidiary of Tube Investments, Ltd., of its ability to supply this metal in a variety of sections, including finned tubes, with mechanical properties in the hot-extruded state, which include a tensile strength of $30-45$ tons per sq. in. and an elongation in the longitudinal direction of 4-10 per cent*.

The problem of overcoming the brittleness of beryllium has been approached by controlling the purity of the metal, by reducing the grain-size and by control of the erystalline orientation. Although the two first avenues can exert beneficial effects, it is the last that, at present, offers the most promising line of attack. As a result of its hexagonal structure, beryllium shows marked anisotropy both of strength and ductility. At ordinary temperatures the main slip occurs on the basal plane and on the prism faces in the $<1120\rangle$ direction; the critical stress needed to initiate basal slip being about one-fifth of that on the prism face. Very little basel slip can, however, take place before fracture occurs, while quite extensive slip can occur on the prism face provided that the orientation is such that slip on the basal plane is

* Chesterfield Tube Co., Ltd. Fabrication of Beryllium Tubes and Sections: a New Structural Metal with Unique Properties. Pp. 16.
(Chesterfield : Chesterfleld Tube Co., Ltd., 1960.) inhibited. As the temperature is raised, the stress necessary to produce prismatic slip falls, and at $500^{\circ} \mathrm{C}$. it is the same for both forms.

Mechanical operations such as rolling or extrusion result in a preferred orientation of the crystals to which hexagonal metals are particularly prone, whence the behaviour of extensively worked material approaches that of a single crystal. As a result, a tensile force applied normally to the basal plane results in a brittle fracture, but a force parallel to that plane leads to considerable ductility. In an extruded flat section, for example, the basal planes tend to lie parallel to the sides of the flat, the longitudinal ductility of the section being high, 5-15 per cent elongation, but transversely, the ductility may be negligible. The extrusion techniques which have now been developed control the orientation of the grains, so that in a tube the basal planes, instead of radiating from the tube axis, are randomly orientated over the cross-section. Bursting tests at $600^{\circ} \mathrm{C}$. have shown 10 per cent expansion at failure for such randomly orientated tubes as compared with 2-4 per cent for tubes with the radial texture.

It would appear that, although beryllium with some degree of ductility has been known for some time, this is an important step forward which, moreover, may well have applications to other hexagonal metals, for example, magnesium. 